Scotland for although there will always be problems the SGMSC through its partnership advisory group in essence promotes a code of good conduct and practice.

JOHN CALLANDER Chairman Scottish General Medical Services Committee

Bo'ness, West Lothian EH51 OPQ

\section{The NHS 1982}

SIR,-I note your letter from $\mathrm{Dr}$ Tony Keable-Elliott (31 July, p 375). Two points of irritation lead to a sweeping generalisation. The previous week he asked a consultant to carry out a domiciliary visit which involved more than two hours' travelling, and it was carried out the next weekday. If he had quoted this only he would have come to a very different generalisation.

If he wishes to publish an appraisal of his NHS service at the local hospital, I challenge him to publish over a six-month period the history of his referrals. Patients would be referred in the following categories-urgent, needing immediate admission, or outpatient appointment with an accompanying letter stating priority as urgent, soon, or routine. Unless this is carried out, the publication of his letter is not worthy of your journal.

David W CaIRns

Amersham General Hospital,
Amersham, Bucks HP7 0JD

${ }_{* *}^{*}$ We sent this letter to Dr Keable-Elliott, who replies below.-ED, $B M F$.

SIR,-Of course there is much good in the NHS, and especially I am grateful to $\mathrm{Mr}$ Cairns for his help at a domiciliary consultation, but this does not alter the fact that a patient referred to a consultant never saw him (or his deputy), and a patient with "routine" varicose veins could not be offered an appointment within three months. Mr Cairns may be content with this state of affairs; I am not. The fault, as I pointed out in my letter, is not with the staff but with the underfunding of the NHS, and why it is "unworthy of your journal" to say so I fail to understand.

TONy KeABLE-ELLIOTT

British Medical Association,

London WC1H 9JP

\section{Prisoners' medicine}

SIR, - With reference to the review in Medicine and the Media (31 July, p 372) of World in Action's programme "Prisoners' Medicine," Dr Henry Rollin attempted to negate some very valid criticisms of the provision for inmates of prisons. Dr Rollin confirmed that persons are sent to prison as punishment not for punishment, and in his last paragraph attempts to reassure the reader that inmates are not deprived of "a good medical service."

The present nursing care for inmates of prisons and borstals is provided by two totally separate services-even the conditions of service are different. For women inmates there exists the prison and borstal nursing service, which consists of State registered and enrolled nurses supplemented by agency nurses when necessary and some nursing auxiliaries. These nurses are recruited as qualified staff. For the male inmates nursing care is provided by male hospital officers, who, as was pointed out in the programme, are discipline officers who have received three months' additional instruction. The standard of care provided is that of a good nursing auxiliary in the NHS. There is no regular or formal system by which these hospital officers can be seconded for statutory training. This two-tier system discriminates against the male inmate in that he is forced, unlike the woman inmate, to receive a poorer quality of service than he would as a normal member of the public. The service is also unsafe in that officers are not able to recognise changes in the physical and emotional state of their charges.

Dr Rollin pointed out that although the prisoners injured in the Wormwood Scrubs riot may have been sutured by hospital officers a proportion of these men are state enrolled nurses. What Dr Rollins did not state was that it is not the policy of the Home Office to recruit or employ qualified nurses in the hospital officer service-the few that exist are in the service by chance. The fact that no inmate suffered as a result of the ministration of the hospital officers is therefore a matter of luck not good organisation. That the officers cope as well as they do is to their individual credit not that of the Home Office or the professionals who condone it.

The post of Chief Nursing Officer to the Home Office was created in 1974 in an attempt to resolve some of these difficulties. The attempt was never developed, and the person appointed resigned in 1978 . The post has been readvertised once and is still not filled in 1982 because the Home Office and Treasury cannot agree on the "grade."

Contrary to Dr Rollin's reassurances, male inmates of prisons are deprived of "a good medical service," to which he agrees they are entitled. The situation will not change while informed members of the profession attempt to cloud anything that implies criticism of the existing service.

R F FISHER

Croydon CR0 5NU

\section{Action for victims of medical accidents}

SIR,-I read Minerva's comment on the organisation Action for Victims of Medical Accidents with interest (7 August, p 445), as I joined (by invitation) its committee for the first three meetings. Peter Ransley had written an excellent play which, I happened to know, was correct in every detail. I wished them well.

I left in the main because circumstances took me outside London but also because I was becoming increasingly uneasy about the attitude of the other members, which was that of confrontation with the doctors. A reasoned approach to influential professional bodies, a panel of independent medical experts, and no-fault legislation were all mentioned as possible remedies, to be dismissed with little discussion.

I did see some of the letters Peter Ransley received. From them, and from my own experience, I am sure that some patients are very negligently treated, that they thereby suffer long-term or permanent disability, and that many cases, especially the undefended ones (which are presumably the more negligent and therefore the more serious), are subject to quite unjustifiable delay. It seems to me quite wrong that in those circumstances it is the most interested parties, the defence societies and the hospital authorities, that decide the amount of compensation offered, and it is high time some truly independent system was devised. If Minerva would like to lead a campaign she can count me in as a founder member. But 'I fear that those who seek justice through Mr Ransley's organisation may find it even more difficult and slower to obtain than at present.

London NW11 6TU

ANNE SAVAge

\section{Drug interaction with} coumarin derivative anticoagulants

SIR,-As the person responsible for editing the final edition of our paper (24 July, p 274) I regret there is an error in that quinidine is included in the list of drugs which have no effect on these anticoagulants. It is also included in the list of drugs expected to potentiate, which is where it should appear.

Dichlorphenazone (Welldorm) is listed as a drug which may potentiate or inhibit. This is deliberate as both reactions have been claimed.

A further comment has been made in relation to propionic acid derivatives where two-fenoprofen and ketoprofen-have been included in the list of drugs which may potentiate while ibuprofen is included in the list of drugs which have no effect. It is apparent opinion varies on this account, and, while there is no good evidence that any of this group of drugs (including naproxen) has a direct effect on the levels of coagulation factors, they all have a mild inhibitory effect on platelets and can be gastric irritants. So they should be used with caution when used in association with anticoagulants.

While there are differences of opinion relating to existing drugs, it is certain that these lists will increase as other drugs, both established and new, are found to interfere with anticoagulants. Whether personal idiosyncrasy exists, in terms of the interaction of some drugs, must await more scientific study.

I am grateful to Dr J C Smith of Mersey Regional Health Authority for his advice relating to propionic acid derivatives.

A A SHARP

John Radcliffe Hospital

Oxford OX3 9DU

\section{Blood pressure and contraceptive use}

SIR,-It is most useful to have confirmation from Dr Kay-Tee Khaw and Professor W S Peart's carefully conducted study (7 August, $p$ 403) of the association between a rise in blood pressure and the progestogen component in the combined oral contraceptive. I am, however, surprised that they should believe that "the oestrogenic component of the oral contraceptive is generally thought to be responsible for the rise in blood pressure." Of course, I have to admit that nobody knows what is "generally thought," because the general thinkers have not been polled on the subject, but evidence suggesting that the effect was unlikely to be associated with the 
oestrogen has been available for many years.

Using data generated in the Royal College of General Practitioners' oral contraception study, I was unable to show in $1974^{1}$ any correlation between reports of hypertension in oral contraceptive users and the oestrogen dose. At the same time, there was a suggestion that the progestogen component might be implicated. Convincing evidence of this association was published in $1977^{2}$ and additional data were made available in $1980 .^{3} \mathrm{I}$ accept that some workers regard conclusions drawn from reports of the occurrence of hypertension as less reliable than analyses of blood pressure measurements, but in retrospect the doubts may not have been entirely justified.

We must also take account of the strong evidence that the excess of arterial disease in oral contraceptive users is associated with the progestogen activity ${ }^{3-6}$ and that this is closely correlated with undesirable changes in highdensity lipoprotein cholesterol concentrations ${ }^{6-9}$ and carbohydrate metabolism. ${ }^{10}$ Clearly, Khaw and Peart's advice to use oral contraceptives with the lowest effective progestogen activity must be emphatically endorsed.

Clifford R Kay Director, Oral Contraception Study RCGP Manchester Research Unit, Manchester M20 0TR

\footnotetext{
Royal College of General Practitioners. Oral contraceptives and health. London: Pitman Medical, 1974

2 Royal College of General Practitioners' Oral Contraception Study. Lancet 1977; i:624.

- Meade TW, Greenberg G, Thompson SG. Br Med

1980 ;280:1157-61. Gynaecol 1981;88:838.

- Kay CR. Am $\mathcal{F}$ Obstet Gynecol 1982;142:762-5.

Briggs MH. British fournal of Family Planning 1979 5:25-8.

Bagget B, Nash HA. Contraception 1980;21:115-20 Wynn V, Niththyananthan R. Am f Obstet Gynecol $1982 ; 142: 766-72$

10 Wynn V. Am $\mathcal{F}$ Obstet Gynecol 1982;142:739-46.
}

\section{Coronary disease}

SIR,-I was very pleased to read Dr J Tudor Hart's recommendation of a prudent diet for the prevention of ischaemic heart disease in general practice ( $31 \mathrm{July,} \mathrm{p} \mathrm{347).} \mathrm{The} \mathrm{near}$ absence of ischaemic heart disease in eas Africa (four cases recognised in Africans in 40 years (1928-68)) and its relationship to a lowfat, low-sugar, high-carbohydrate diet is well known. The good correlation of the changing diet among Japanese immigrants is less well recognised (table). ${ }^{1}$ Morris $e t a l^{2}$ showed that an increase of cereal fibre was particularly important, with five times the number of cases of coronary thrombosis occurring among the one-third of a group of 337 southern Englishmen who ate the least fibre over 20 years when compared with the third who ate most cereal fibre. ${ }^{2}$

In the present uncertainty about the relative importance of the different factors one can only recommend a reduction in total dietary fat, particularly the saturated portion, a reduction of sugar, and an increase in unrefined carbohydrate, particularly that containing cereal fibre.

\section{Great Parndon,
Harlow, Essex}

'Shun-Ichi Y. In: Trowell HC, Burkitt DP, eds Western diseases. London: Arnold, $1981: 337-42$. Morris JN,
1307-14.

SIR,-We were interested in the article on the prevention of coronary disease by Dr Julian Tudor Hart (31 July, p 345) and note with approval that the prevention lobby is at last gaining momentum in this country. The fact that coronary disease varies widely in incidence in different parts of the world suggests that environmental factors are of major importance. Smoking does not seem to induce the disease in Japan and therefore appears to act only in conjunction with certain dietary factors.

There is a general pessimism in the United Kingdom that individuals will not readily alter their dietary habits, as has been the case with such beneficial results on the incidence of coronary disease in the United States. This view is probably partly based on the difficulty in reducing alcohol and cigarette consumption. We suggest that this is a false analogy, because alcoholics in particular are a special group with particular addictive difficulties, and there is evidence from the growing number of health food shops and health magazines that a sizeable proportion of the population would indeed be willing to listen to dietary advice. We suggest that part of the problem is that the information is confusing to the lay public. Advice on the consumption of saturated fats, carbohydrates, and fibre mean little or nothing to the lay housewife without even a superficial knowledge of nutrition. There is quite clearly a major information and comprehension block, which must be overcome.

We therefore decided to study two specific foods, meat and eggs, which often form the main constituent of a meal. Assuming three major meals per day there is a total score of 21 meals per week. Subjects were asked how many times they ate meat. Sixty-five patients who had survived a myocardial infarct established by electrocardiographic and enzyme studies were compared with 177 age- and sex-matched controls. The mean meat score in the myocardial infarct patients was 10.938 compared with 8.102 in the controls $(p<$ 0.001 ). Egg consumption per week was also assessed, and the mean for the infarct group was 4.194 compared with 2.869 in the controls $(p<0.001)$. A full report and mathematical analysis will be published elsewhere but the evidence suggests that a diet containing a maximum of four meat meals per week and three eggs per week would significantly reduce the risk of coronary disease. Such simple advice is easily understood and deserves wide dissemination.

RONALD FinN

M A SMITH

J R GREEN

Departments of Medicine and Computational and Statistical Science, University of Liverpool and the Royal Liverpool
Hospital, Liverpool L7 8XP

Should every survivor of a heart attack be given a beta-blocker?

SIR,-The series "Should every survivor of a heart attack be given a beta-blocker ?" was an excellent review of the state of knowledge by Professor J R Hampton (3 July, p 33), Professo A Breckenridge (p 37), and Professor Geoffrey Rose (p 39). We would like to offer comments on three issues: cardioselective versus nonselective beta-blockers, the importance of replicating findings, and the interpretation of cumulative mortality curves.

Firstly, as pointed out by Professor Hampton the Multicentre International Trial of practolol reported selective benefit for patients with anterior infarction. Interestingly enough, the same findings were observed in the Goteborg metoprolol trial (A Hjalmarson, personal communication). It is intriguing that the two largest trials of cardioselective beta-blockers showed a benefit restricted to patients with anterior infarcts. None of the large trials of non-selective beta-blockers has reported such results. This could be a chance finding but may also be real. Only continuing or further trials can resolve this question.

Secondly, we agree with the view that the value of very early treatment has not been established. Of six randomised placebocontrolled trials where intravenous treatment was started on admission (followed by oral treatment), three ${ }^{1-3}$ showed a higher and three $^{4-6}$ a lower mortality in the beta-blocker group. Only the single-center Goteborg metoprolol trial ${ }^{5}$ reported a significant $(p<0.03)$ short-term reduction in mortality. McIlmoyle et $a l,{ }^{6}$ using the same dosage of metoprolol, could not replicate the Swedish results. This raises the question whether the findings from the Goteborg group, which has extensive experience in beta-blocker treatment, can be generalised to other settings. In multicentre trials patients from varied geographical, socioeconomic, and medical care facilities are enrolled. Thus, results of collaborative trials enable one to generalise the findings with more assurance.

Thirdly, there seems to be a tendency to overinterpret cumulative mortality curves. Time segments of the curves are defined post hoc and form the basis for strong conclusions. We would like to caution against this practice. Clinical trials are usually designed to have the statistical power to detect a treatment effect over the entire patient follow-up phase. Thus, comparisons based on time segments will suffer from insufficient power and therefore large variability. This problem increases as one moves to the right on the curve. For example, in the beta-blocker heart attack trial ${ }^{7}$ and the Norwegian timolol trial $^{8}$ less than $10 \%$ of all deaths occurred after the average length of follow-up (25 and 17 months in the two trials, respectively). Moreover, only analyses beginning at time zero, when because of randomisation the study groups are comparable, are completely valid. Because of different mortality patterns in the beta-blocker and placebo groups
Changes in diet among fapanese immigrants to Hawaii and US $A^{1}$

\begin{tabular}{lcccl}
\hline & Starch $\left({ }^{\prime},{ }_{0}\right)$ & Sugar $\left({ }^{\circ}\right)$ & Fat $\left({ }_{0}^{\prime}\right)$ & Comment \\
\hline Japanese in Japan & 52 & 11 & 15 & No fibre figures given \\
Hawaiian Japanese & 33 & 16 & 33 & Fourfold increase in saturated fats \\
Californian Japanese & 30 & 17 & 38 & Further rise of saturated fats \\
\hline
\end{tabular}

